\title{
Teaching Pediatric High-Value Care Strategies at the Bedside
}

Emily Wong, MD, Chad Vercio, MD

"A 4 month-old previously healthy, full-term female is brought to the ED for difficulty breathing and decreased feeding. She is found to be RSV positive, mildly dehydrated, and hypoxic on room air. She is admitted for treatment of bronchiolitis."

Case:

A 4 month-old previously healthy, full-term female is brought to the ED for difficulty breathing and decreased feeding. She is found to be RSV positive, mildly dehydrated, and hypoxic on room air. She is admitted for treatment of bronchiolitis.

On hospital day 3 , she requires a high-flow nasal cannula at 7 LPM $40 \% \mathrm{FiO} 2$. She has been unable to be weaned from this level for the last two days. The night resident is paged to speak with the father at the bedside. The father is worried about his daughter's lack of improvement and requests a chest $x$-ray because one has not been done during the admission, and he feels the medical team has not been thorough enough.

\section{What would you advise your learner to do? What resources could you point him or her towards?}

The concepts of medical over-diagnosis, over-treatment, and overuse or low-value care, long important topics in adult medicine, have received increasing attention in pediatrics $(1,2)$. However, promoting and teaching high-value care in pediatrics, with value defined as quality over cost (3), has met unique challenges. There can be a perception that because the medical spending on children is significantly smaller than adults, it is less valuable to spend time in an already crowded curriculum to focus on highvalue care. It can also be perceived that when focusing on highvalue care, one is claiming that children use too much of a shared resource, which would be seen as socially undesirable (4). However, we believe modeling high-value care practices in children is

Readers can also follow NEONATOLOGY

via our Twitter Feed

@NEO critical because it focuses on unnecessary and potentially harmful interventions as well as decreasing the overall costs in pediatrics. Expectations for what constitutes appropriate evidence-based care practices are set early, both for medical learners as well as for families and patients themselves. Once set, expectations are difficult to change.

Furthermore, the SARS-CoV-2 pandemic is highlighting the ease with which low-value treatments can be inadvertently thrust into the spotlight through politicization. Politicians have inaccurately touted positive responses to unproven remedies such as Regeneron and hydroxychloroquine as "cures." This can create a public perception that treating a patient always involves medication, leading to even more medical waste as well as the potential for harm (5). However, a clinician must communicate clearly with patients and their families and, at times, protect them from unnecessary interventions they may desire.

Potential barriers to providing high-value care are multifactorial and can include: lack of evidence; poor familiarity with existing guidelines; local culture; time pressures relating to productivity; time required to explain to patients why tests or treatments are not indicated; and pressures to practice defensive medicine (6). With a relative weakness of evidence-based and large randomized clinical trials in pediatrics, it is even more important to stay aware of existing practice guidelines and professional resources and to teach learners early to seek these out. To address our case, the clinical practice guidelines for bronchiolitis by the American Board of Pediatrics is a good starting point for clinicians and medical trainees alike (7). Choosing Wisely, the American Board of Internal Medicine campaign to encourage physicians and patients to reconsider specific medically unnecessary interventions has also grown rapidly in recent years to include many general pediatric and pediatric subspecialty recommendations (8).

\section{"Choosing Wisely, the American Board of Internal Medicine campaign to encourage physicians and patients to reconsider specific medically unnecessary interventions has also} grown rapidly in recent years to include many general pediatric and pediatric subspecialty recommendations (8)." ",

Fear of malpractice litigation is a commonly cited concern among physicians who knowingly order low-value interventions, such that up to $93 \%$ of physicians surveyed in Pennsylvania reported practicing defensive medicine (9). However, the reality is that practicing defensive medicine does not necessarily protect against 
malpractice claims, which can be arbitrary - nearly $40 \%$ of injuryrelated malpractice claims in one study were found not to involve medical errors (10). This is an important concept to impart upon medical learners, as perceptions surrounding malpractice are formed early in training. Instead, behaviors to prevent malpractice should focus on nurturing good communication and bedside manner: listening to families and patients carefully, accurate and timely documentation of decision-making, discussion of side-effects and risks of tests and treatments. When mistakes do occur, it is essential to communicate openly. While historically, physicians have been conflicted about error disclosures due to fear of litigation or embarrassment, standards issued by the Joint Commission on Accreditation of Healthcare Organizations identify disclosure of harmful medical errors as an ethical obligation. Prominent open disclosure programs throughout the nation have demonstrated a significant reduction in litigation expenses and payouts (11).

A major component of combating medical overuse involves managing patient expectations. It is a common perception that more testing leads to better care. This is at times exacerbated by legitimate pressures the clinician may face about patient satisfaction, which is often tied to reimbursement. Effective communication will often contribute more to the parent/patient's satisfaction than the management plan itself. Elements of discussion should center around the fact that parents/patients desire a clear diagnosis, shared decision-making, and acknowledgment that their concerns are valid (Figure 1).

\section{"As pediatricians and medical educators, we are unique in advocating for children in the national dialogue about overtreatment and overdiagnosis."}

As pediatricians and medical educators, we are unique in advocating for children in the national dialogue about overtreatment and overdiagnosis. This process begins with addressing self-identified barriers to practicing high-value care, utilizing professional and educational resources, cultivating one's ability to hold productive conversations with patients and families about low-value interventions and testing, and setting appropriate expectations about care by modeling this behavior for medical learners and young patients.

\section{References:}

1. Coon ER, Quinonez RA, Moyer VA, Schroeder AR. Overdiagnosis:

\section{Figure 1: Tips for talking to patients about doing less}

Determine the patient or family's primary concerns

- "What do you think is going on?"

- "What are you most worried about?"

- Consider unique barriers: financial, transportation, etc.

Explain your reasoning clearly while acknowledging the patient's concerns

- "I understand why you would be worried about [diagnosis], but the good news is you don't have any concerning signs or symptoms."

Show the patient you are on their side

- "I wish I could prescribe you antibiotics, but it may make the situation worse."

Create a clear follow-up plan; review red-flag signs and symptoms

- "My colleague is on call this weekend and can discuss with you if things change. Please call or be seen in urgent care if $[\mathrm{x}, \mathrm{y}, \mathrm{z}]$."

\section{Respond calmly to resistance}

- If attacked: take a breath; attack likely has a deeper cause and has nothing to do with the clinician. Resist the urge to retort or walk away.

- If met with silence: ask open-ended questions. Seek to understand. Some silence is ok; do not feel obligated to fill it. 
how our compulsion for diagnosis may be harming children. Pediatrics. 2014;134(5):1013-1023

2. Coon ER, Young PC, Quinonez RA, Morgan DJ, Dhruva SS, Schroeder AR. Update on pediatric overuse. Pediatrics. 2017;139(2):e20162797

3. Berwick DM, Hackbarth AD. Eliminating waste in US health care. JAMA. 2012;307(14):1513-1516

4. Ralston SL, Schroeder AR. Why it is so hard to talk about overuse in pediatrics and why it matters [published online August 21,2017]. JAMA Pediatrics. doi:10.1001/jamapediatrics. 2017.2239

5. https://lowninstitute.org/when-evidence-becomes-politicized-how-do-we-talk-about-low-value-carel

6. Overcoming Barriers to High Value Care. ACP High Value Care Online Curriculum: https://www.acponline.org/clinicalinformation/high-value-care

7. Ralston SL, Lieberthal AS, Meissner HC, et al. Clinical practice guideline: the diagnosis, management and prevention of bronchiolitis. Pediatrics. 2014;134(5):e1474-e1502.

8. https://www.choosingwisely.org

9. Studdert DM, Mello MM, Sage WM, et al. Defensive medicine among high-risk specialist physicians in a volatile malpractice environment. JAMA. 2005 Jun 1;293(21):2609-17. [PMID: 15928282]

10. Studdert DM, Mello MM, Gawande AA, et al. Claims, errors, and compensation payments in medical malpractice litigation. N Engl J Med. 2006 May 11;354(19):2024-33. [PMID: 16687715]

11. Gallagher TH, Studdert DM, Levinson W. Disclosing harmful medical errors to patients. N Engl J Med. 2007 Jun 28;356(26):2713-9. [PMID: 17596606]

Disclosures: The authors do not have any relevant disclosures.

NT

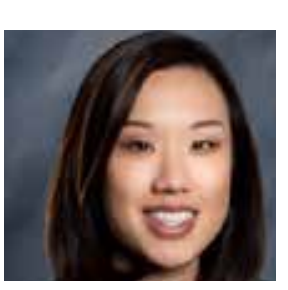

Corresponding Author

Emily Wong, MD, FAAP

Assistant Professor, Pediatrics

Loma Linda University School of Medicine

Department of Pediatrics

E-mail: EWWong@llu.edu
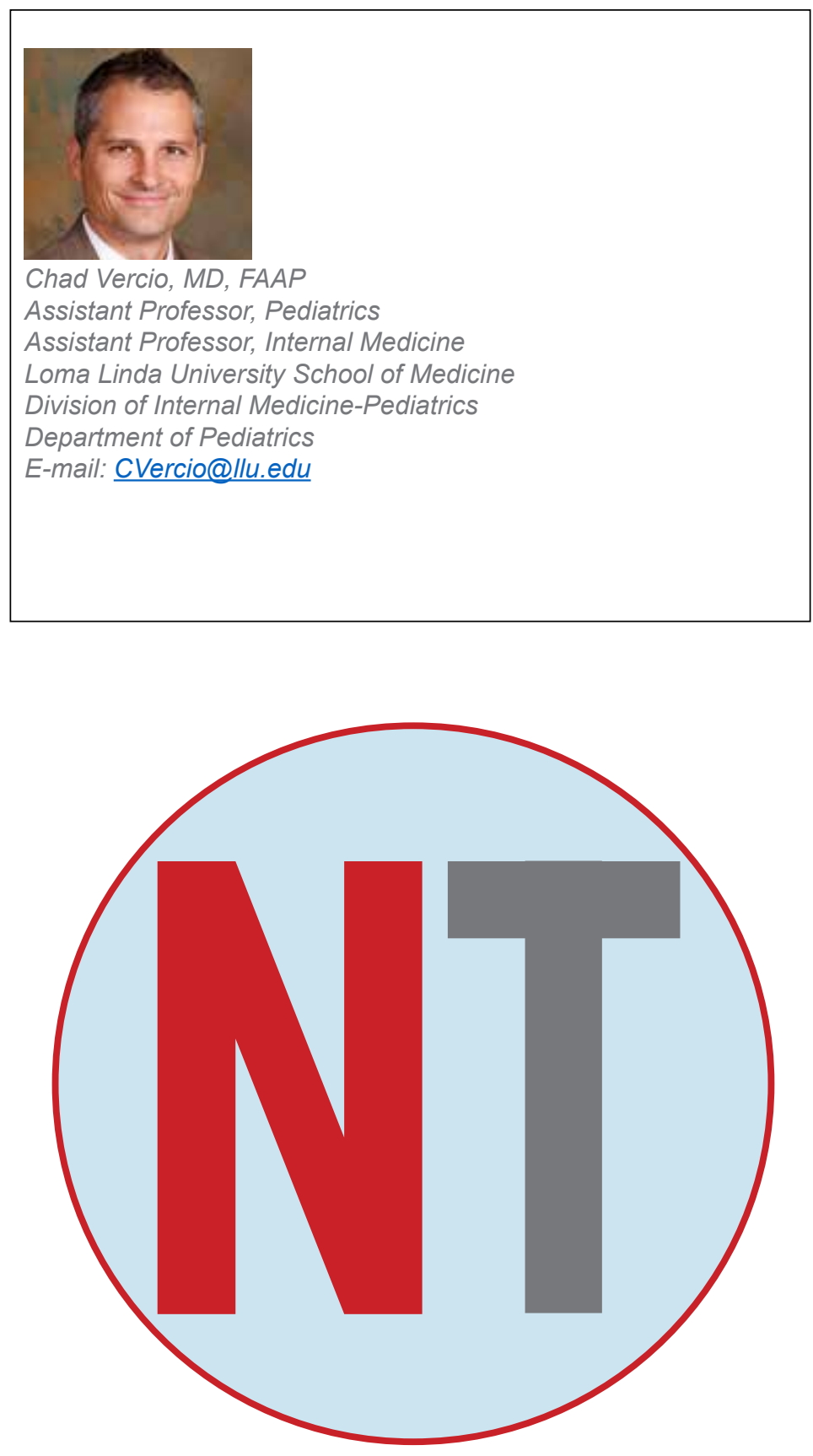

New subscribers are always welcome! NEONATOLOGY TQDAY

To sign up for a free monthly subscription, just click on this box to go directly to our subscription page 